\begin{tabular}{ll}
\hline $\begin{array}{l}\text { Vector-Borne Zoonoses in India: } \\
\text { Systematic gap analysis and Implications }\end{array}$ & Journal of Development Economics and \\
Mor policy-level interventions & A Peer-Reviewed Open Access \\
& International Journal \\
& ISSN: 25825119 (Online) \\
& Crossref Prefix No: 10.53422 \\
& $09(11), 96-126$, January-March, 2022 \\
& @Center for Development Economic Studies \\
& (CDES) \\
& Reprints and permissions \\
https://www.cdes.org.in/ & https://www.cdes.org.in/about-journal/ \\
\hline
\end{tabular}

\title{
Vector-Borne Zoonoses in India: Systematic gap analysis and Implications for
} policy-level interventions

\author{
P. Basker ${ }^{1}$, Simmi Tiwari $^{2}$, Ajit Shewale ${ }^{3}$, Tushar Nale ${ }^{4}$, and Sujeet Kumar Singh $^{5}$
}

\begin{abstract}
Crimean Congo Hemorrhagic fever (CCHF), Kayasanur Forest Disease (KFD), and Scrub Typhus (ST) are re-emerging Vector-borne zoonotic Diseases (VBZD) in different parts of the world including India. Still, factors associated with the epidemiological components, agents, hosts and environment of these diseases are needed to probe to intersect them to break the cycle of disease transmission. National One Health program is the most appropriate to prevent and control Zoonotic diseases as it involves multisectoral collaboration. The present article is made to propose novel strategies for a nationwide campaign. It is based on gaps identified in existing

1 Consultant Entomologist, Division of Zoonotic Diseases Programme (DZDP)- National one health Programme for prevention \& Control of Zoonoses (NOHP-PCZ), National Center for Disease Control (NCDC), 22, Sham Nath Marg, Delhi-110 054, India.

${ }^{2}$ Joint Director, Division of Zoonotic Diseases Programme (DZDP)- National one health Programme for prevention \& Control of Zoonoses (NOHP-PCZ), National Center for Disease Control (NCDC), 22, Sham Nath Marg, Delhi-110 054, India.

3 Deputy Director, Division of Zoonotic Diseases Programme (DZDP)- National one health Programme for prevention \& Control of Zoonoses (NOHP-PCZ), National Center for Disease Control (NCDC), 22, Sham Nath Marg, Delhi-110 054, India.

4 Deputy Director, Division of Zoonotic Diseases Programme (DZDP)- National one health Programme for prevention \& Control of Zoonoses (NOHP-PCZ), National Center for Disease Control (NCDC), 22, Sham Nath Marg, Delhi-110 054, India.

5 Director, National Center for Disease Control (NCDC), 22, Sham Nath Marg, Delhi-110 054, India22, Sham Nath Marg, Delhi-110 054, India.

Corresponding author: Dr.P.Basker, Consultant Entomologist, Division of Zoonotic Diseases Programme (DZDP, National Center for Disease Control(NCDC),22, Sham Nath Marg, Delhi-110 054, India.
\end{abstract}


prevention and control activities towards VBZD in different states of India by a Questionnairebased survey. It was conducted by circulating a questionnaire to all states. In addition to that, the virtual discussion was made with State Health Officers, State Nodal Officers, and State Entomologists. A literature survey was made from 1965 to 2020 to incorporate the findings under the concept of One health and supplement it in the present strategy towards the prevention control of CCHF, KFD, and ST. Further, it has been ascertained from the study that gaps identified have been utilized to fill interfaces between human, animal, and environmental health. In these points of view, observed information has been combined with the existing strategies to form a novel guideline that can be followed in all states of India for the effective prevention and control of VBZD concerning CCHF, KFD, and ST. Its way forward has been discussed in this article.

\section{Keywords: CCHF, entomological surveillance, KFD, Scrub Typhus.}

\section{Introduction}

Crimean Congo Hemorrhagic Fever (CCHF) and Kyasanur Forest Disease (KFD) have been prevalent in a few states of India and at the same time, Scrub Typhus has been reported in the many States of India concerning the Integrated Disease Surveillance Programme (IDSP), Government of India. Tick-borne Crimean Congo Hemorrhagic Fever Virus (CCHFV) is a threat to public health and it's widespread, found in Europe, Asia, Africa, the Middle East, and the Indian subcontinent. In 2011, CCHF was reported in Gujarat, and its spread was found in Rajasthan, Goa, and Maharashtra (WHO, 2018). The circulation of CCHFV is found unnoticed in many species of ticks and several vertebrate hosts. As a result, the potential for zoonotic spillover from ticks and animals to humans is difficult to resolve (Sorvillo et al., 2020). The emergence and re-emergence of CCHF have been identified in the form of new foci in several parts of the world including the Balkan countries, Southwest Russia, the Middle East, India, and Spain due to anthropogenic factors, such as changes in agricultural activities, habitat fragmentation, and importation of infected animals and ticks (Estrada-Pena et al., 2010; Spengler et al., 2018). Information on the geographical distribution of the CCHF Vector Hyalomma ticks, multistage life cycle and host preferences and network between multi-sectoral and multidisciplinary collaborations on disease information would be supplemented for the development of new strategies for the prevention and control of CCHF (Estrada-Pena et al., 2010; 2007; 2013a; Formenty et al.,2007).

Scrub typhus is an acute febrile illness of variable severity that is caused by Orientia tsutsugamushi (formerly Rickettsia). It is transmitted to humans by an arthropod mite vector of the Trombiculidae family. The public health importance of this disease is underestimated because of difficulties with the clinical diagnosis and lack of laboratory methods in many geographical areas (Hornick., 2000).

The burden of ST is more in rural Asia and it is causing up to $20 \%$ of hospital admissions (Brown, 1976). Scrub typhus is prevalent in many parts of India too. It is under diagnosed in India due to its non-specific clinical presentation, limited awareness and low index of suspicion among clinicians, and lack of diagnostic facilities. The rickettsial diseases once thought to have been eradicated from India are re-emerging and has been reported from 
various parts of India (Mahajan, et al., 2006; Varghese, et al.,2006; Kamarasu et al., 2007 Mittal, et al.; 2012; Subhalakshmi, et al.,2014).

To prevent and control scrub typhus, personal protection, rodent control and habitat modification, clearing of vegetation and chemical treatment of soil are highlighted as these activities lead to a break cycle of transmission from chiggers and humans to other chiggers. There is an urgency to conduct periodical susceptibility studies over chemicals used for mite control with the coordination of animal and human health interfaces under "One health".

Kyasanur Forest Disease (KFD) is a tick-borne viral hemorrhagic fever transmitted by the bite of 'Ticks' infected with the KFD Virus. The disease was first reported in 1956 in 'Kyasanur Forest' of Shivamogga district, Karnataka, India. Hence, the disease was named Kyasanur Forest Disease. Currently, KFD is being reported from the States along with the Western Ghats ranges, namely: Karnataka, Kerala, Tamil Nadu, Goa, and Maharashtra. The first report of the occurrence of fever in people having a history of forest exposure in the Kyasanur area dates back to 1956 (Subhalakshmi, et al.,2014).

KFD Virus is reported from India only. The virus is found structurally similar to the Russian Spring-Summer Encephalitis (RSSE) Virus. The other viruses which are closely related to KFD are Omsk Hemorrhagic Fever Virus in Siberia, Alkhurma Virus in Saudi Arabia, and Nanjianyin Virus in China. Since 1956, the transmission dynamics of KFD is seen as it slowly spread to neighborhood States, Tamil Nadu, Kerala, and Maharashtra from Karnataka. From 1957-1971, the disease was confined to the Shivamogga district alone. During 1972, cases were reported from neighboring districts and it had been spread to new districts of Karnataka and its neighboring States from 1980 to 2016. In 2017, the Gadag district of Karnataka has reported tick pool positive. In 2019, the Mysuru district (Heggada Devena Kote) has reported 2 human positive cases; and in the same year, Hassan district has reported 1 human positive, 2 tick pool positives, and 1 monkey positive.

Towards factors that are prone to KFD, the topography of villages situated in the abode of Western Ghats and evergreen deciduous and semi-deciduous forest on the slopes mixed with bamboo and shrub jungle at the edges and inhabitants visit the forest for firewood collection frequently are conducive to have human cases of KFD.

The existing Prevention and control strategies of KFD are comprehensive as most of intercedes is along with agent, host, and environment. In the present article, efforts have been taken to compile scattered established factors under "One health" to full fill interfaces between human, animal, and environmental health to formulate novel strategies towards the prevention and control of CCHF, KFD, and ST that can be followed all States in India uniformly. Since it is a prerequisite for further discussion among experts in the field of VBZD, this article is considered the most important.

\section{Material and Methods}

Since February 2021, a systematic search was conducted to collect scientific research articles on Emerging and Reemerging Zoonoses in India through Pub Med, Google Scholar, Research Gate, and Web of Science using key-words like Emerging Zoonoses, Reemerging Zoonoses, and Strategies on control and prevention of Vector-Borne zoonotic Diseases in India. Concerning One health, Epidemiological profile and geographical risk map for emergence and reemergence of three high-priority Zoonoses CCHF, KFD, and Scrub typhus 
(ST) from 1965 to 2020 (55 years) were probed for global and Indian context to arrive at probable comprehensive strategies which can be followed countrywide.

The review of publications/literature for the last 55 years related to the concept of the present study was reviewed thoroughly on epidemiology, control, and prevention of VBZD. The guidelines given in different articles have been compiled taking cognizance of the concept of "One health" so that all states/Union Territories (UT) in this country may follow it uniformly. National review meeting on entomological surveillance on Vector Borne Zoonotic Diseases (VBZD) for Public Health personals, veterinarians and entomologists, flagged certain issues and the same has also been addressed in the guidelines.

The questionnaire-based surveys were undertaken to ensure the gaps towards control and prevention of VBZD. There were 24 questions framed under four groups namely 'A "for general information; $\mathrm{B}$ for entomological surveillance. $\mathrm{C}$ for Vector control measures and $\mathrm{D}$ for the impact of inter-sectoral coordination program (ISCP). The response from the informants were compiled and presented in Tables-1, 2, and 3). The outcomes of the questionnaire-based surveys were considered for developing strategies towards control and prevention of CCHF, KFD, and ST.

In addition to that, relevant publications, activities are undertaken against CCHF, KFD, and ST those are followed the principle of "One health was carefully scrutinized. It was proved that the identified interfaces to be filled between environmental, animal, and human health whether they have capabilities to intersect the components of Epidemiological triad towards control and prevention of these diseases in India.

The Questionnaire-based survey was analyzed to find out gaps in existing strategies towards control and prevention of CCHF in India. It is revealed that 73 participants responded from 18 States out of 29 States and 8 Union Territories in India. The respondents for surveys, State Surveillance Officer (SSO), State Nodal Officer (SNO), State Health Officers, veterinarians from Regional Centers, State, Regional and District Entomologists. The following objectives are formulated for developing new strategies through framed structured questionnaire for the prevention and control of VBZD, Such as

1. To understand the current status, ongoing activities and to undertake gap analysis for vector Borne zoonotic diseases prevalent in respective states,

2. To discuss the prevalence of vectors, ecological niches of vectors along with current strategies on their control.

3. To discuss the status of the state entomologist network and the way forward for further strengthening.

\section{Results and Discussion: \\ Response to the questionnaire}

It has been observed that $61.1 \%$ of States have no Standard Operating Procedure (SOP) for conducting tick and mite surveys; $5.5 \%$ of states reported indigenous cases of CCHF and $22.5 \%$ of states to have cases of KFD and 100\% States reported ST. Since 4 States alone have cases of CCHF and KFD, the remaining States are free from these diseases at present. It is noticed that $100 \%$ of States have disease-wise stratification and line listing whereas $50 \%$ of States do not have baseline data of VBZD and their vectors. About the vector surveillance against Scrub Typhus, 33.3\% of States have done in which 19\% States have 
recorded the vector of ST. It is known that CCHF and KFD reported States alone conducted entomological surveillance and reported their Vectors. The remaining 14 States have not been reported CCHF and KFD and therefore no information on the existence of respective vectors. While answering the question on the VBZD status with the laboratory confirmation, only 50\% of States responded "yes" and some of them stated it as a mixed infection of leptospirosis, ST, and Dengue. The present status of VBZD in India is given in Fig-1.

In framed Questionnaire, Group-B contains questions on entomological surveillance. From the respondents, the following have been observed, as $33.4 \%$ of States (6 States) are followed some guidelines for tick and mite collection. Further, $61.1 \%$ of States have not been conducted mite collection in places where VBZD cases reported for some other reasons. There was no information on the fauna of tick and mite in States those are free from CCHF and KFD. It is about $72.2 \%$. From $61.1 \%$ of States, those reported CCHF and $66.6 \%$ KFD reported States, there was no periodical and systematic entomological collection observed. On the importance of the faunistic and periodical entomological collection, 5.5\% states stated that it is felt the need. Overall, there are $44.4 \%$ of States have been collected vectors after the positive case of VBZD and 50\% of States have identified scrub Typhus vector Leptotrombidium deliense. Ultimately, it is shown from the responses over the questionnaire and virtual discussion, there is a need for new strategies that can be followed countrywide. The summary of proposed strategies is given in Figure- 2 at a glance.

The question was asked to know about the SOP on tick and mite control that followed by States. In its response, $22.2 \%$ of States have known about mite and tick control with chemicals, but there was no information about the methodology that followed by them. Other than chemical control, $16.6 \%$ of States did environmental sanitation through clearing bushes and habitats of rodents, and in and around residents of VBZD positive cases reported. Insecticide susceptibility tests have not been conducted by all States due to lack of infrastructure in the laboratory, manpower, and not known the standard Operating Procedures (SPO). Further, 72.2\% of States have well known the importance of susceptibility tests, and 55.5\% of States have known that the resistance is common to vector arthropods over the spectrum of insecticides/acaricides as they have been exposed to vector control in Malaria prevention and control programme.50\% of States emphasized that the co-ordination of Veterinary departments with public Health and its implication, States need logistic supports of both the State and NCDC (Table-3).

\subsection{Outcome of the Discussion made from virtual National Review meeting.}

- CCHF, KFD is prevalent in 4 states whereas Scrub Typhus (ST) is reported from 18 states of India.

- Vouching for all observations in the entomological surveillance from the framed questionnaire, it is known that methodology/guidelines for tick and mite collection have to be improved in all the states. It is suggested that faunistic study in VBZD vulnerable places as it is the most vital to understand the activities of ticks and mites over some time, species composition, etc.

- Towards vector control measures, such as Chemical control with the standard operating procedure (SOP), the selection of insecticide/acaricide based on the susceptibility test, formulation, and methods on the application of insecticide and acaricide; rotation of insecticide based on the determination of efficacy (susceptibility status) and resistance status of insecticides are urgently required. 
- To exploit the concept of "One Health" in control and prevention of VBZD, the department of public health should take efforts to coordinate between Veterinary, Animal husbandry, department of wildlife, department of forest, and stakeholders related to human and animal health are indispensable as it is found to be lacking in most of the states in India.

\section{Strategies employed for the control and prevention of VBZD concerning Review of literature}

The following evidence-based information and findings in publications that bridges between human, animal, and environmental health have been taken and implicated to incorporate them for surveillance, case findings, diagnosis, and evaluating the program with the insight of the concept of "One Health". Some of them are highlighted here

- Under the environmental health, meteorological factors particularly climate change, manmade activities like, land use are sources for human contact with ticks and mites vectors, distribution of animal and density of ticks and mites, factors deteriorating animal health and livestock production by ticks and mites have been taken for the development of control strategies to stratify as disease vulnerable area that can be used for instituting early containment measures and keep a vigil on it forever.

- Virus transmission pressure has the property to take part in control strategy as it expresses on tick infestation.

- The modes of virus transmission are known by bites of ticks and secondly through contact with viremic animal blood during the slaughtering process and human-tohuman transmission occurs in a household or nosocomial setting when no proper personal protective equipment is worn.

- The cross-sectional studies on CCHF and other VBZD are helpful to predict diseasevulnerable places.

- To develop strategies on entomological surveillance, the following basic entomological indicators have been considered, such as 1. Species composition, abundance, and seasonality2. Vector behavior: feeding location and time 3. Quality assurance and residual efficacy monitoring 4 . Insecticide susceptibility 5 . Insecticide resistance intensity and 6 . Mechanism of resistance.

As improved entomological surveillance, there are three indicators namely Identification of vectors infectivity; Determine longevity of vector and determine the host preference of the vectors are identified. On the entomological surveillance over CCHF, the expansive geographic range of Hyalomma ticks, their multi-staged life cycle, and corresponding variability in host preferences are a few to predict CCHFV in humans, animals, and ticks and this information would be appropriate to find interfaces among them for the development of strategies (Estrada-Pena, et al.,2010;2007;2013b).

In addition to that, national programs in coordination with WHO regional offices and networking with collaborating centers' laboratories, wildlife conservation society, and relevant organizations are also be implicated for the strategy updating towards the effective control and prevention of VBZD (Formenty et al, 2007). 


\section{Strategies found towards the prevention and control of KFD}

Probing the literature on the strategies to prevent and control KFD, NCDC had been taken efforts to scrutinize guidelines by experts in 2017 and 2018. Following it, Karnataka state (the first case was reported in Shivamogga District) has been strengthening interventions against agent, host, and environment and compiled as Operation Manual. Since this disease is prevalent in India, strategies identified and refined are adequate at this juncture. Some observations are highlighted as they include for the coordination of human health, animal health, entomological, environmental aspects and role of stakeholders, etc., for the effective control and prevention of KFD, the following are found to be important. Such as

- The occurrence of monkey deaths in areas is the indication of KFD and it may lead to human cases since it is usually preceded by epizootic in the monkey population in the area.

- Careful investigation on the Occurrence of monkey death.

- Activities on Collection of ticks in the proximity of dead monkey.

- Establish the presence of KFD Vectors in the outbreak area.

- Identify the natural hosts of vectors ticks both in domestic and wild animals,

- Identify the source of tick infestation to man.

- If the area has no previous history of the disease and the known vector species are absent, the priority for investigation is virus isolation in ticks that have not been designated as vectors species along with sero surveillance in domestic and pet animals are needed (Operational manual-Kyasanur Forest Disease.2020; CD Alert, 2018).

\section{Strategies found towards the prevention and control of Scrub Typhus (ST) from the Literature Survey.}

- Investigating the outbreak of scrub typhus, the following important parameters are needed under special attention 1) confirmed cases of ST and other spotted fever group and typhus groups 2) chigger index, and 3. Sero surveillance in rodents, pet animals, and vectors. These parameters are to be correlated concerning the time and space of the year when cases occurred.

- The chigger index has relevance to the presence of vector trombiculid mite i.e. Leptotrombidium deliense group.

- Mite collection should be made from 10 animals in and around positive cases of ST. In which domestic animals, cattle, goats, dogs, pets, and feral animals are suggested with the coordination of Animal husbandry, forest, and wild Life Institute.

- It is known that the Chigger index is significant to forecast and determine the magnitude of the problem.

- In addition to that, a unique observation in mites' larval character has been found in the literature that larvae of mites are remarkably hardy and can survive weeks of freezing or immersion in water. It might be taken in areas those lodged with water after monsoon with signs and symptoms of ST (Traub et al., 1968). 
Chigger index: It is calculated as several chiggers infested by a single host. A single case of scrub typhus must occur in a month was estimated to be 0.6 chiggers per suncus murinus and 0.6 chiggers per Rattus spp. It is therefore essential index of 1 may be taken as a critical value necessary for the occurrence of a single case of scrub typhus.

\section{Susceptibility Test for Insecticide Resistance}

Limited studies have been carried out on the susceptibility of ticks to insecticides. The existing methodology consists of topical application of a known volume of insecticide in aqueous or alcoholic solution in a series of two-fold dilutions and to observe mortality after an exposure period of 24 hrs. Thus, LC50 or LC90 values can be determined. In the KFD area, it has been shown that species of the genus Haemaphysalis show higher susceptibility to Benzene Hexa Chloride (BHC) (banned since 1997) as compared to other conventional acaricides (Operational Manual-Kyasanur Forest Disease.2020).

In selecting a suitable laboratory test for acaricide resistance, the following requirements must be satisfied.

- The test should be sensitive enough to identify resistance early in its emergence. It should also cover the full range of chemical groups that are in use, including the most recently developed molecule.

- The diagnostic test should be simple and inexpensive.

- It should provide a rapid and reliable result, and be suitable for standardization among laboratories in many countries.

- The most widely used in vitro tests are bioassays applied to larvae and engorged female ticks.

- Resistant strains of ticks can be diagnosed by internationally recognized standardized test protocols and reporting methods. One of the tests called the Larval Packet Test (LPT) advised by experts since 1975 and it has been promoted by FAO (Shyma, 2013; Lovis, 2013). It is suggested to include it in the proposed strategy for conducting a periodical susceptibility test for the effective tick and mite control.

\section{Evaluation of the control and prevention activities}

Since Indices are having potential properties to evaluate the activities carried out in VBZD affected area, it receives more attention from public Health managers, Veterinarians, and entomologists. It has been taken efforts to identify the appropriate indices to incorporate in control strategies as they have a significant role to evaluate/appraise the VBZD control and prevention programs. Based on that, some of the indices found in the literature have been implicated in this article to build up new strategies. Such as Tick density, Chigger index, Prevalence rate of mites, mean intensity of ectoparasites, Tick Infection rate, and Host Infestation rate are a few. However, indices like Normalized Difference Vegetation Index (NDVI) and its application in spatial and temporal studies have been seen in the literature. It is understood that this kind of index has a role in the assertion of the existence/presence of herbivore and non-herbivores disease reservoirs and their ecological niches. Since rodents to wild animals are hosts and reservoirs of the pathogen, the utility of a novel index like NDVI is 
credential and it may incorporate into a new strategy (Nathalie Mauricio Lima., Kyrre Kausrud., 2011).

\section{Components for formulating new Strategies on prevention and control of VBZD}

To transform into policy that could be adopted by all States uniformly, i) present strategies followed by states, ii) outcome and analysis of the questionnaire, and iii) developments on the VBZD prevention and control found in the publication have been compiled in the present study. The following components are more appropriate and they have attributes to bridge gaps found in the existing strategies followed by States at present. The suggested components hereunder might be useful to refine further in the future based on the "One health concept as that of the Indian context. Further, these components have properties for the prevention and control of VBZD through a collaborative, multidisciplinary, and multisectoral approach that can address urgent, or potential health threats at the human-animalenvironment interface at sub-national, national, regional, and global levels. The features of each component are briefed.

Surveillance: It is integrating the various components that determine the occurrence of disease in a place. Ideally, the system will compile data from human surveillance (Human cases); Veterinary surveillance (Animal health); entomological surveillance (Arthropod vectors bionomics, geographical distribution, the population of vectors identification, control measures, etc.), and environmental surveillance for addressing risk factors.

Human Health: Surveillance for predicting human cases is done by Active (Door to Door surveillance by health personals) and passive surveillance (institutional surveillance i.e. persons who have ailments will utilize nearby health facilities like Primary Health Center (PHC), Government Hospitals (GH), Tertiary care hospital, private nursing homes, etc.). From these surveys, it is possible to pick up probable cases of VBZD with signs and symptoms and case definitions of VBZD, CCHF, KFD, and ST. In active surveillance, only suspected cases will be predicted by field staff with the case definition after the capacity building is imparted to them. To obtain information on VBZD from private Nursing homes, the guidelines in the Integrated Disease Surveillance Programme (IDSP) might be useful as it has access to receive from private clinics in districts by the District Public Health officials.

Animal Health: Even though animal health is being monitored through passive surveillance, active surveillance should be improved through the coordination of public health primary care system under the supervision of district-level Public health functionaries as zoonoses are interconnecting to each other. In this context, the infestation of ectoparasites among animals, host preference of vectors, existing control measures with insecticide/acaricide, insecticide susceptibility and resistance, animal reservoirs, causal agents, and its circulation among domestic, pet, and feral animals by sero surveillance are integral activities of veterinarians, public health entomologists, environmentalists and wildlife institutes in India, etc. Thus, the network and solutions found for interfaces are implicated to incorporate them for developing strategies for the prevention and control of VBZD such as CCHF, KFD, and ST.

Environmental Health: On environmental health, data on ecological, meteorological, and climate changes are taken from all resources. In which, the following are found most appropriate. Such as Trends in global travel, trade, urbanization and tourism, data on 
temperature and humidity, biodiversity, climate change, and land-use change and management, and Landscape composition. Since this information is vital to understand the epidemiology of diseases, the collection of data about them might be incorporated for developing a new strategy.

Entomological surveillance: Under this surveillance, it has been observed that both the public health and veterinary entomologist's role are so important as much as established factors have been found in the literature. Among them, the most important things have been included for the characterization and bring them into existence in the strategies. The entomological surveillance system was designed according to the entomological and epidemiological context and well-defined objectives. Based on that, the following are highlighted such as 1 . Risk assessment2.Early warning systems3.Identification of the vector species involved in transmission event.4. Identification of circulating pathogen strain 5. Optimizing vector control in time and space.6. Guidance for source reduction campaign7.Insecticide resistance and 8. Evaluating the efficacy of vector control under entomological surveillance (Frederic Jourdain, 2019). Similarly, studies for the prevention and control of CCHF with the concept of One Health found in the literature under three realms such as environmental health; animal health, and human health have been considered for the development of a new strategy. (Sorvillo, et al., 2020).

\section{Process for implementing and updating entomological surveillance (ES) systems}

As a way forward for the entomological surveillance system, the following are comprised. Such as 1. Establishment of entomological surveillance2.Determination of relevant areas and time for surveillance implementation.3. Determination of data sources and data collection methods 4. Capacity building for selective competent staff.5. Analysis and interpretation of the information.6. Dissemination of surveillance findings for action and 7. Evaluation of surveillance activities.

\section{Other factors associated with Tick and Mite Vector}

Inherent properties associated with behavior, physiology of vectors have been found in tick and mite in which host-seeking behavior called multiple host cycle, transstadial, and transovarial properties are a few. In Transstadial transmission, the pathogen remains with the vector from one life stage (stadium) to the next. It is common in ticks and mites. As its significance, the vector itself acts as a reservoir. Transovarial transmission (transmission from parent to offspring via the ovaries) occurs in certain arthropods vectors including ticks, mites, and Aedes species of mosquitoes as they transmit pathogens from parent arthropod to offspring arthropod.

In addition to that, the remarkable behavior of the chigger vectors of mites Leptotrombidium akamushi and Leptotrombidium deliense and Leptotrombidium scutellare has been noticed as it survives weeks of freezing or immersion in water (Traub ., Wisseman ., 1974). 
Entomological surveillance (ES) takes part in the Evaluation of Control Programmes.

The following Indices that are scattered in the literature have been compiled for the evaluation of the VBZD control and prevention.

\section{Ticks related Indices}

1. Tick Density is expressed as Man Hour Density (MHD): It is measured through the total number of Ticks collected in an hour by one manpower. If ticks are collected from animals, density is expressed as the number of ticks/animals. The critical density derived from repeated observation in disease transmission will be helpful to forecasting the diseases when we undertake routine ES in a vulnerable place.

2. Mean Intensity of ectoparasites from host animals: Total number of ectoparasites collected/Number of hosts infested with ectoparasites (Paulraj Philip Samuel, et al., 2021).

3. Tick Infection Rate: The detection of viral antigen or genomic fragments in tick vectors. It is calculated by the number of tick vectors positive with CCHFV/Number of Ticks tested X 100. Its critical Rate is found 2.78\% (Spengler, Bente., 2017; Leggiadro, 2017; Estrada-Peña,et al.,2013b).

\section{Mites related Indices}

1. Prevalence of mites: Number of Hosts infested with ectoparasites/Total number of hosts examined (Paulraj Philip Samuel et al., 2021).

2. Chigger Index: It is exclusively for Mite Borne Disease. It is measured by the number of chiggers infested by a single host.

3. Host vector infestation rate: Proportion of hosts infested by the vector/ host species in which vector species composition might be given.

\section{Spatial and Temporal based Index}

NDVI: Normalized Difference Vegetation Index (NDVI): This Index is taken from the literature as the latest development in ecology to predict herbivore and non-herbivore animals in a place (Nathalie Mauricio Lima., Kyrre Kausrud., 2011). Since it provides a vital role to predict different types of hosts as well the reservoirs of the pathogen in a place, it might be considered to incorporate in strategies.

\section{Strategies on the control and prevention of KFD}

Scrutinizing the literature on the strategies on the prevention and control of KFD, it is found that well-defined measures are delineated by the experts in the National Center for Diseases Control (NCDC), Delhi in 2018 (Communicable Disease Alert. 2018 NCDC publication), in which the importance of multi-sectoral coordination of various departments (Public Health, Animal husbandry, and Veterinary colleges, Forestry, wildlife, Revenue, Education, Women, and child welfare, Information and broadcasting and Non-Governmental Organization) and their responsibilities have been given as guidelines for impending outbreaks and activities to be carried out during and post focal outbreaks. Similarly, the 
operation manual for KFD is ascribed epidemiology, diagnosis, vector surveillance, bionomics of vectors, and vector control in which susceptibility status of vectors over the spectrum of chemicals might be added for the rotation of insecticides or acaricides.

\section{Discussion}

The main objectives of this article are to bring out salient features of major epidemiological components, agents, hosts, and environment to fit them for interventions towards prevention and control of CCHF, KFD, and Scrub typhus (ST). Probing the literature on recent interventions of VBZD by intersecting components in the epidemiological triad, appropriate publications have been taken in the present study to include into the present strategies followed by States.

It is well known that One health comprising multi-sectoral and multi-disciplinary approaches that enable to fill interfaces between environmental - animal and human health. The studies undertaken towards the prevention and control of VBZD adopting the concept of One health were also discussed in this article. From this observation, the probable prevention and control strategies have been formulated under the following i.surveillance and its outcomes ii. Environmental health iii. Entomological surveillance iv.Process for implementing and updating entomological surveillance systems. v.Evaluation of the control and prevention of VBZD concerning Entomological surveillance vi.Established factors regarding Bionomics of vectors, Behavior of Ticks and mite Vectors, etc (Table-4and5).

On disease surveillance and its outcomes, the active, passive, and sentinel surveillances have been highlighted to predict cases in the community with the signs and symptoms of CCHF, KFD, and ST. It is known that cases of these diseases will be identified as probable and suspected by Medical and Para medicals respectively. To improve this surveillance, the case definition of each disease is a prerequisite. For clinical case findings of VBZD, signs, and symptoms of each disease should be characterized by a sudden onset of symptoms such as high fever, headache, myalgia, and petechial rash, frequently followed by hemorrhagic state and, occasionally, multi-organ failure (Ansari, et al.,2014). In addition to that, obtaining periodical data on these diseases from the tertiary care hospitals and private nursing homes is required to strengthen the surveillance. All this information should be compiled and send daily, weekly, and monthly based on the magnitude of the problem to the district headquarters and in turn to the concerned State along with a line listing of cases confirmed by either the gold standard or reliable diagnostic tools available in the district itself. Since this flow of information has already been established in the Integrated Diseases Surveillance Programme (IDSP) in India, a fine-tune must be required to include them for VBZD surveillance. Thus, it is integrating the various components that determine the occurrence of disease, and also ideally, the system will compile data from human surveillance (Human Cases). As its kinds, Veterinary surveillance (Animal host), entomological surveillance, Environmental surveillance (environmental risk factors), and laboratory surveillance have also been proved that they are required to intervene in disease transmission as well as for filling up interfaces as stated in the concept of One Health. Based on its importance, it is emphasized in the new strategies for the prevention and control of VBZD.

It has been known that an effective surveillance system provides data on disease incidence and prevalence, establishes high-risk behaviors or practices at vector-host-human 
interfaces, and implementation of preventive measures. Further, it has been implicated to have networks with WHO-based surveillance in collaboration with other organizations working for both the human and animal health sectors including the FAO and World organization for Animal Health (OIE), Non-Governmental Organization (NGO), Wildlife Conservation Society, and academic partners (Formenty, et al.,2007).

Scrutinizing the reasons for emerging CCHF as new foci in several parts of the world including India, it is known that it is due to anthropogenic factors, such as changes in agricultural activities, habitat fragmentation, and importation of infected animals and ticks (Estrada-Peña,2010; Spengler and Bente, 2017). In addition to that the influences of climatic changes have also been suggested (Duygu et al., 2018; Estrada-Peña et al., 2013a; Zinsstag, et al., 2011).

The concept of One Health recognizes the interconnectedness of human, animal, and environmental health. It is an approach to disease prevention that efforts may address human health in a broader context, making change and intervening in an interdisciplinary manner (Ertugrul, et al.,2012).

Surveillance is the foremost component for the development of the National strategy to prevent and control VBZD. Under this component, important factors established in human, animal, and tick surveillance have been analyzed concerning CCHF, KFD, and ST and brought to include in the present strategies. As far as CCHF is concerned, the following factors prevailed under human health such as i. Case definition finds probable and suspected cases of CCHF based on signs and symptoms of the disease in the institution and community ii. To prevent and control the disease well in advance, Stratification based on the incidence of cases and their significance will be helpful iii. Sero surveillance determines confirmed cases and the routes of transmission (Nasirian, 2019). About the advantages of human surveillance for CCHF, the possible stratification based on the incidence of cases, potential for disease transmission to humans, and presence of surveillance system are accountable (Spengler, et al., 2018; Ertugrul, et al., 2012; Gunes, et al., 2009). Further, entomological surveillance is the most important even in places freed of $\mathrm{CCHF}$ as vectors themselves act as reservoirs of CCHFV.

Since animals are reservoirs of pathogen and serving as hosts for ticks, sero surveillance is mandatory. Some important activities are discussed to include them in the development of present strategies. They are i. serological surveys in domestic, pet, and wild animals with the coordination of Veterinary and Animal Husbandry departments to ascertain geographic range and relative levels of CCHF circulation, ii. Information on the movement of animals that can also complicate serological data interpretation, as the location in which the sample was collected may differ from the location of exposure (Spengler, et al., 2016; Hoogstraal, H., 1979).

In tick surveillance, the following points are highlighted to include in the present strategies such as i.since ticks are the vector and reservoir of CCHFV, information on maintaining the virus in nature through transstadial, transovarial transmission, multiple host preference and co-feeding behavior, xenodiagnosis are being vital in ticks to predict the virus circulation ii. Faunistic study undertaking for ensuring the presence of vector species ticks and mites and its population is the most appropriate as it may be necessary to support the natural circulation of the virus (Hoogstraal, 1979; Gargili, et al., 2017; Gonzalez, 1991; Shepherd et al., 1989., Bente, et al., 2013). When the co-existence of other species of ticks is 
identified along with the primary vector of CCHF, Hyalomma species, the role of other species in CCHFV maintenance and transmission is not defined even though the virus has been detected in several other tick genera (Amblyomma, Rhipicephalus, Dermacentor and Ixodes); however, data on the vector competence of these species is obscured (Gargili, et al., 2017). In this situation, other species of ticks may supplement in new geographic regions.iii. Factors related to the expansion of disease in a novel region are the most important as reservoir vectors importation is possible through migratory birds (Palomar et al., 2013; Chisholm, 2012; De Liberato, 2018; Buczek, 2020; Kar et al, 2020). It is described that the factors that determine the long-term maintenance and persistence of the virus in ticks over time, including transstadial and transovarial transmission in the sustainability of CCHFV in ticks' population (Logan et al., 1989).

Further, its importance is ascertained through human cases after the detection of viral antigen or genomic fragments in tick vectors. For example, in 2010, before reports of human cases in Spain, CCHFV RNA was detected in that country in Hyalomma lusitanicum and Hyalomma marginatum ticks at a rate of $2.78 \%$, which was similar to the CCHFV tick infestation rate of other endemic countries in Europe including Kosovo, Bulgaria, and Albania (Chisholm,2012; De Liberato,2018;).And also, it is observed that these data were important in confirming the established spread of CCHFV into western Europe 7 years before the first human case was documented in Spain in 2017(Leggiadro,2017; Estrada-Peña,2012). Additionally, viral antigen was detected in ticks in Iran over 20 years before autochthonous human cases were described (Sureau, 1980). In another observation, it was noticed that focus on tick collection from cattle can be a sensitive indicator of the presence of virus circulation in a given geographic area because cattle can be infested by a greater density of Hyalomma species than small ruminants (Wilson et al., 1990).

Probing the transmission dynamics of tick-borne diseases, there is three-level of dynamics have been observed namely, ecological, transmission dynamics, and probability of human infection dynamics. In ecological dynamics, both animals and ticks take part by their distribution, density, and pathogen prevalence, and infection intensity. If ecological dynamics has reached its threshold, it transforms into transmission dynamics where the route of exposure have been flown through virus prevalence at slaughter, immature biting rate, survival of the virus in blood and tissue, and tick survival in nature and ultimately it leads to the dynamics of the probability of human infection by human exposure based on human behavior, adult biting rate, dose and route of exposure. The probability of human infection again depends on physical and intrinsic barriers, host tissue susceptibility and permissiveness and, immune response. Towards identifying factors that should be fitted from each phase of dynamics in developing present strategies, almost all of the components in ecological dynamics have properties as all possibilities of computing host and tick distribution; host and tick density; pathogen prevalence by the cross-sectional study and ultimately infectivity rate in human as well in ticks.

In transmission dynamics, some of them can study directly and some of them are determined in the laboratory. For example, virus prevalence in slaughter areas, virus survival in blood and tissues, etc. can be possible by molecular tools. But human behavior is studied by observation. Immature and adult biting behavior of ticks is possible in the laboratory by animal models. Similarly, the components, physical and intrinsic barriers are qualitative in 
which host tissue susceptibility in animal and immune response are possible in the probability of human infection dynamics.

Indices, tick density, chigger index, the prevalence rate of mites, mean intensity of ectoparasites, tick infection rate, minimum requirement of chigger needed per human case per month, and host-vector infestation rate have been brought based on their significance described in ecological, disease and probability of human infection dynamics. Since these indices have attributes to evaluate the prevention and control of tick and mite-borne diseases CCHF, KFD, and scrub typhus, these are considered to be the most important parameters to include in the present new strategies (Table-4).

In addition to that, a new index is coming up in the recent publication, like Normalized Difference Vegetation Index (NDVI). It attributes to development in ecology, particularly in predicting herbivores and non-herbivores distribution, abundance, and history of traits in space and time with the advancement in Geographical and satellite-based Information systems. This kind of application would be a novel approach to identify the spillover of tick and mite to their hosts and disease reservoirs from small mammals to wild animals. In this point of view, this index is more appropriate to include in the strategies.

In mites, a unique observation found in the literature is that chigger vectors are remarkably hardy and can survive weeks of freezing or immersion in water. This extraordinary property may supplement in case detection mechanism and constitute contingent plan for implementing containment measures for monsoon-related diseases preventions including ST (Traub, et al.,1968).

On the disease transmission under Environmental health, global travel, trade, urbanization and tourism, climate change and land-use changes, meteorological data, temperature, Relative Humidity (RH), biodiversity, landscape composition, and frequent importation of Hyalomma species ticks into novel regions via migratory birds or animal trade (e.g., livestock) is of particular concern for the expansion of endemic areas are major factors described in the literature. Therefore, information about these aspects supplements the prevention and control strategies as in the concept of One Health (Palomar, 2013; Chisholm, et al., 2012; De Liberato, 2018; Buczek, 2020).

About entomological surveillance, it is described extensively in ecological and transmission dynamics rather than the probability of human infection dynamics. Similarly, in vector-borne diseases, malaria, filariasis, dengue, and chikungunya prevention and control, more information has been found and inherent properties related to bionomics of vectors are extensively discussed. Some of them are, host preferences, longevity, resting habits, exophilic, endophilic resting habits of mosquitoes, physiology of ovaries to determine oviposition, age determination, etc are attributed towards their control activities described elaborately (Frederic Jourdain, 2019).

\section{IEC and Personal Protection}

Simultaneously, extension on Information Education and Communication (IEC) on hosts, agents, and environment of these diseases are also take part towards their prevention and control in which personal protection to avoid ticks and mites to human contact is the most important.Further, the importance of Personal Protection Equipment (PPE) while visiting tick and mite borne disease-prone areas, wearing masks and aprons in hospitals to avoid CCHF 
through nosocomial infection, and advocating preventive measures against $\mathrm{CCHF}$ to butchers while slaughtering is also suggested.

\section{Culmination of this article}

The discussion was made so far on Human-Animal -Environment has been intertwined based on the available information in the literature to constitute the present probable strategies for making policy decisions for the prevention and control of VBZDs to follow all member states in India. It is given as a gist in the flow chart (Figure-2).

\section{Conclusion}

The document has been aligned with the concept of One Health and has addressed the challenges with feasible strategic solutions for the prevention and control of VBZD. The outcome of the National review meeting on the entomological surveillance, and the way forward have been crucial while incorporating the expert's opinion in the document. It is expected that the publication of such guidelines in a scientific journal will further strengthen it through its peer review and wider circulation.

The formulated National strategies for the control of VBZD consist of surveillance in which, human, animal, and environmental health have been included towards case findings, reservoir status, circulation of pathogens, ectoparasites and vectors, mode of disease transmission, vector control measures, and susceptibility status of acaricide, etc. In its support, entomological surveillance is dealt with separately as many as inherent properties, transstadial, transovarial, transmission, co-feeding, and multiple hosts seeking behavior of ticks and mites that take part in diseases transmission. The identified parameters, the density of vectors, larval index, prevalence rate, mean intensity, infection rate, host infestation rate, etc, have also been explained in detail as they are crucial for forecasting and evaluating the prevention and control measures over VBZD regarding CCHF, KFD, and ST. The interrelationship between Human-Animal-Environmental health has been an important chapter of the guidelines and it is shown in a flow chart at a glance (Figure-2).

\section{Credit authorship contribution statement}

Dr.Simmi Tiwari; investigation, writing-review \& editing. Dr.P.Basker: Conceptualization, writing - original draft. Dr.Ajit Shewale: Methodology, Resources, supervision, writing-review, editing. Dr.Tushar Nale: Resources, methodology, writingediting.

\section{Declaration of Competing Interest}

The authors have no conflicts of interest in this article. 


\section{Acknowledgments}

This study is undertaken by Division of Zoonotic Disease Programme (DZDP)National One Health Programme for prevention \&control of zoonoses (NOHP-PCZ), National Center for Disease Control (NCDC), Ministry of Health and Family Welfare, Government of India, Delhi-54, through the National Review Meeting (virtual) on entomological surveillance in which all member states of India have participated on 18.02.2021 under the chairmanship of the Director of NCDC Dr.Sujeet Kumar Singh. We are grateful to the Director for his encouragement to bring out this article. We thank Dr.Monal Daptardar, Consultant Public Health, Dr.Dipti Mishra Consultant Veterinary, Miss. Trishala Sharma, Data manager, and all staff in the DZDP, NCDC, for their valuable assistance by all means in arrangements for the review meeting and preparing this manuscript. We are very grateful to Mr.S.Sridharan, former Chief Entomologist, Government of Tamil Nadu, and Dr.PK.Srivastava, Former Joint Director, NVBDCP, Delhi as they read this manuscript and suggested improving the entomological surveillance part.

\section{References}

1. Ansari, H., Shahbaz, B., Izadi, S., Zeinali, M., Tabatabaee, S.M., Mahmoodi, M., Holakouie-Naieni, K.,Mansournia, M.A., (2014). Crimean-Congo hemorrhagic fever and its relationship with climate factors in southeast Iran: A 13-year experience. J. Infect. Dev. Ctries., 8, 749-757. DOI: https://doi.org/10.3855/jidc.4020.

2. Bente, DA., Forester, NL., Watts, DM., et al. (2013). Crimean-Congo hemorrhagic fever: history, epidemiology, pathogenesis, clinical syndrome, and genetic diversity. Antiviral Res. 100(1):159-89.

3. Brown, GW., Robinson, DM., Huxsoll, DL., et al.,(1976). Scrub typhus: a common cause of illness in indigenous populations. Trans R Soc Trop Med Hyg. 70:444-448.

4. Buczek, A.M., Buczek, W., Buczek, A., Bartosik K.,(2020). The potential role of migratory birds in the rapid spread of ticks and tick-borne pathogens in the changing climatic and environmental conditions in Europe. Int J Environ Res Public Health. 17(6): 2117.Published online 2020 Mar 23. DOI: 10.3390/ijerph17062117.

5. CD Alert. (2018). National Centre for Disease Control Directorate General of Health Services https://www.cdc.gov/vhf/kyasanur/pdf/factsheet.pdf;1-10.

6. Chisholm, K., Dueger, E., Fahmy, N.T., Samaha, H.A.T., Zayed A., Abdel-Dayem, M., Villinski, J.T., (2012). Crimean-Congo hemorrhagic fever virus in ticks from imported livestock, Egypt.Emerg. Infect. Dis., 18,181-182.

7. De Liberato, C., Frontoso, R., Magliano, A., Montemaggiori, A., Autorino, G.L., Sala, M., Bosworth A., Scicluna, M.T., (2018). Monitoring for the possible introduction of 
Crimean-Congo hemorrhagic fever virus in Italy based on tick sampling on migratory birds and serological survey of sheep flocks. Prev. Vet. Med. 149, 47-52.

8. Duygu, F., Sari, T., Kaya, T., Tavsan, O., Naci M. (2018). The relationship between Crimean-Congo hemorrhagic fever and climate: Does climate affect the number of patients? Acta Clin.Croat. 57, 443-448.

9. Ertugrul, B., Kirdar, S., Ersoy, O.S., Ture, M., Erol, N., Ozturk, B., Sakarya, S. (2012). The seroprevalence of Crimean-Congo hemorrhagic fever among inhabitants living in the endemic regions ofWestern Anatolia.Scand. J. Infect. Dis. 44, 276-281.

10. Estrada-Peña, A., Mertens, M., Schmidt, K., Ozkul, A., Groschup, M.H., (2013). The impact of Crimean-Congo hemorrhagic fever virus on public health. Antivir. Res. 98: $248-260$.

11. Estrada-Peña, A., Palomar, A.M., Santibáñez, P., Sánchez, N., Habela, M.A., Portillo A., Romero, L., Oteo, J.A., (2012). Crimean-Congo hemorrhagic fever virus in ticks, Southwestern Europe, Emerg. Infect. Dis. 18,179-180.

12. Estrada-Peña, A., Zatansever, Z., Gargili, A., Aktas, M., Uzun, R., Ergonul O., Jongejan, F., (2007). Modeling the spatial distribution of Crimean-Congo hemorrhagic fever outbreaks in Turkey. Vector Borne Zoonotic Dis., 7, 667-678.

13. Estrada-Peña,A., Ruiz-Fons,F., Acevedo,P., Gortazar,C.,de la Fuente, J. (2013). Factors driving the circulation and possible expansion of Crimean-Congo hemorrhagic fever virus in the western Palearctic. J. Appl. Microbiol. 114, 278-286.

14. Estrada-Peña,A., Vatansever,Z., Gargili, A., Ergönul, (2010). The trend towards habitat fragmentation is the driving the spread of Crimean-Congo hemorrhagic fever. Epidemiol. Infect. 138, 1194-1203.

15. Formenty, P., Schnepf, G., Gonzalez-Martin, F., Bi, Z., (2007). International surveillance and control of Crimean-Congo hemorrhagic fever outbreaks. In CrimeanCongo Hemorrhagic Fever: A Global Perspective; Springer: Dordrecht, The Netherlands, pp. 295-303. ISBN 9781402061066

16. Frederic Jourdain, et al., (2019). Towards harmonization of entomological surveillance in the Mediterranean area. PLOS Neglected Tropical Diseases.1-28.

17. Gargle, A., Estrada-Peña, A., Spengler, J.R., Lukashev, A., Nuttall, P.A., Bente, D.A.,(2017). The role of ticks in the maintenance and transmission of Crimean-Congo hemorrhagic fever virus: A review of published field and laboratory studies. Antivir. Res. 144. DOI: 10.1016/ j.antiviral.2017.05.010. 
18. Gonzalez, J.P., Cornet, J.P., Wilson, M.L., Camicas, J.L., (1991). Crimean-Congo hemorrhagic fever virus replication in adult Hyalomma truncatum and Amblyomma variegatum ticks. Res. Virol., 142, 483-488.

19. Gunes, T., Engin, A., Poyraz, O., Elaldi, N., Kaya, S., Dokmetas, I., Bakir, M., Cinar, Z.,(2009). Crimean-Congo hemorrhagic fever virus in the high-risk population, Turkey. Emerg. Infect. Dis. 15, 461-464.

20. Hoogstraal, H., (1979).The epidemiology of tick-borne Crimean-Congo hemorrhagic fever in Asia, Europe, and Africa. J. Med. Entomol. 5, 307-417.

21. Hornick, RB. Rickettsial Diseases. (2000). [Chapter 371] In; Bennet JC., Plum F., editors. Goldman: Cecil Textbook of Medicine .21st ed. Philadelphia, USA: WB Saunders Company; p.1911-2.

22. Ivo Elliott, Isabelle Pearson, Prabin Dahal, Nigel, V., Thomas, Tamalee Roberts., Paul N.Newton., (2019). Scrub typhus ecology: a systematic review of Orientia in vectors and hosts.Parasites \& Vectors Volume 12,: 513 https://doi.org/10.1186/s13071-019$\underline{3751-\mathrm{X}}$.

23. Jones, L.D., Davies, C.R., Steele, G.M., Nuttall, P.A., (1987). A novel mode of arbovirus transmission involving a non-viremic host. Science, 237, 775-777.

24. Kamarasu, K., Malathi, M., Rajagopal, V., Subramani, K., Jagadeeshramasamy, D., Mathai, E., (2007). Serological evidence for wide distribution of spotted fevers \& typhus fever in Tamil Nadu. Indian J Med Res. 2007; 126: 128-30.

25. Kar, S.,Rodriguez, S.E., Akyildiz, G., Gajimat, M.N.B., Bircan, R., Mears, M.C., Bente, D.A.,Keles, A.G., (2020). Crimean Congo hemorrhagic Fever virus in tortoises and Hyalomma egyptian ticks in Easty Thrace, Turkey: Potential of the cryptic transmission cycle. Parasites Vectors,13. SSN: 1756-3305.

26. Leggiadro, R.J., (2017). Autochthonous Crimean-Congo hemorrhagic fever in Spain. Pediatric. Infect. Dis. J. http://dx.doi.org 0891-3668 / 1532-0987.

27. Logan, T.M., Linthicum, K.J., Bailey, C.L., Watts, D.M., Moulton, J.R.,(1989). Experimental transmission of Crimean-Congo hemorrhagic fever virus by Hyalomma truncatum Koch. Am. J. Trop. Med. and Hyg., 40, 207-212.

28. Lovis, L., Reggi J., M.,Berggoetz, M., Betschart, B.,Sager, H.,(2013). Determination of Acaricide Resistance in Rhipicephalus (Boophilus) microplus (Acari: Ixodidae) FieldPopulations of Argentina, South Africa, and Australia With the Larval Tarsal Test. J. Med. Entomol. 50(2): 326-335.; DOI: http://dx.doi.org/10.1603/ME12127 . 
29. Mahajan, S K., Rolain, J M., Kashyap, R., et al. (2006). Scrub typhus in the Himalayas. Emerg Infect Dis 12:(10); 1590-2 .

30. Mittal, V., Gupta, N., Battacharya, D et al. (2012). Serological evidence of rickettsial infection in Delhi. Indian J Med Res. 135[4]:538-541.

31. Nasirian, H.(2019). Crimean-Congo hemorrhagic fever (CCHF) seroprevalence: A systematic review and meta-analysis. Acta Trop. 196, 102-120.

32. Nathalie Mauricio Lima., Kyrre Kausrud.,(2011). The Normalized Difference Vegetation Index (NDVI): unforeseen successes in animal ecology. Climate Research.46:15-27, DOI: 10.3354/cr00936.

33. Olson, JG., (1979). Forecasting the onset of a scrub typhus epidemic in the Pescoders Islands of Taiwan using daily maximum temperatures. Trop.Geogr Med.; 31:519524.

34. Operational manual-Kyasanur Forest Disease (2020). Directorate of Health and Family welfare services, Government of Karnataka, pp.100.

35. Palomar, A.M., Portillo, A., Santibáñez, P., Mazuelas D., Arizaga J., Crespo A., Gutiérrez, Ó., Cuadrado, J.F.,Oteo, J.A., (2013). Crimean-congo hemorrhagic fever virus in ticks from migratory birds, Morocco.Emerg. Infect. Dis., 19: 260-263.

36. Paulraj Philip Samuel., Renu Govindarajan., Ranganathan Krishnamoorthi., Jaganathasamy Nagaraj., (2021). Ectoparasites of some wild rodents/shrews captured from Scrub typhus reported area in Tamil Nadu, India. International Journal of acarology.1-4.

37. Shepherd, A.J., Swanepoel, R., Cornel, A.J., Mathee, O.,(1989). Experimental studies on the replication and transmission of Crimean-Congo hemorrhagic fever virus in some African tick species. Am. J. Trop. Med. Hyg., 40, 326-331.

38. Shyma, KP., Sachin Kumar, A K., Sangwan, Anil Kumar Sharma., Gaurav V Nagar DD., Ray Srikant A Ghosh., (2013). Acaricide resistance status of Rhipicehalusp (Boophilus) microplus and Hyalomma anatolicum collected from Haryana.Indian Journal of Animal Sciences 83 (6): 591-594.

39. Sorvillo T E., Sergio, E., Rodriguez, Peter Hudson., Megan Carey Luis, L., Rodriguez Christina, F., Spiropoulou, Brian H., Bird Jessica, R., Spengler Dennis, A., Bente (2020). Review Towards a Sustainable One Health Approach to Crimean-Congo Hemorrhagic Fever Prevention: Focus Areas and Gaps in Knowledge.Trop. Med. Infect. Dis. 5, 113: 1- 28. 
40. Spengler, J.R., Bente, D.A., (2017). Crimean Congo Hemorrhagic fever in SpainNew arrival or silent resident? N.Engl. J. Med. 377-384.

41. Spengler, J.R., Bente, D.A., Bray, M., Burt, F., Hewson, R., Korukluoglu, G., Mirazimi, A., Weber, F., Papa,A. (2018). Second international conference on Crimean-Congo hemorrhagic fever. Antivir. Res. 150.

42. Spengler,J.R., Bergeron, É., Rollin, P.E., (2016). Seroepidemiological studies of Crimean-Congo hemorrhagic fever virus in domestic and wild animals. PLoS Negl. Trop. Dis. 10, e0004210.

43. Subhalakshmi, MUS., Madisetty, MK., Prasad, AK., et al. (2014). Outbreak of scrub typhus in Andhra Pradesh- Experience at a tertiary care hospital Assoc Physician India. 82:490-496.

44. Sureau, P., Klein, J.M., Casals, J., Digoutte, J., Salaun, J., Piazak, N., Calvo, M., (1980). Isolation of Thogoto, Wad Medani, Wanowrie, and Crimean-Congo hemorrhagic fever viruses from ticks of domestic animals in Iran Hyalomma anatolicum, Hyalomma asiaticum, Alveonasus lahorensis; isolates, epidemiology. Ann. Virol.131: 185-200.

45. Traub R., Wisseman CL Jr., (1974). The ecology of chigger-borne rickettsiosis (scrub typhus). J Med Entomol. 11:237-303.

46. Traub, R., Wisseman Charles, L., Wisseman., (1968). Ecological Considerations in Scrub Typhus.2.vector species. Bull.Wld Hlth Org.39:219-230.

47. Varghese, GM., Abraham, DC., Mathai, D., et al.(2006). Scrub typhus among hospitalized patients with febrile illness in south India. Magnitude and Clinical Predictors. J Infect. 52:56-60.

48. WHO, (2018). Crimean Congo Hemorrhagic Fever (CCHF) R\&D Roadmap Meeting; World Health Organization (WHO). Geneva, Switzerland.

49. Wilson M.L., LeGuenno B., Guillaud M., Desoutter D., Gonzalez, J.P., Camicas J.L.,(1990). Distribution of Crimean-Congo hemorrhagic fever viral antibody in Senegal: Environmental and vectorial correlates. Am. J.Trop. Med. Hyg. 43, 557-566.

50. Zinsstag, J., Schelling, E., Waltner-Toews, D., Tanner, M. (2011). From "one medicine" to "one health" and systemic approaches to health and well-being. Prev. Vet. Med. 101: 148-156. 
Table-A1 Details of Questions under the Group-A which is meant for General Information on Vector-Borne zoonotic Diseases (VBZD) in India.

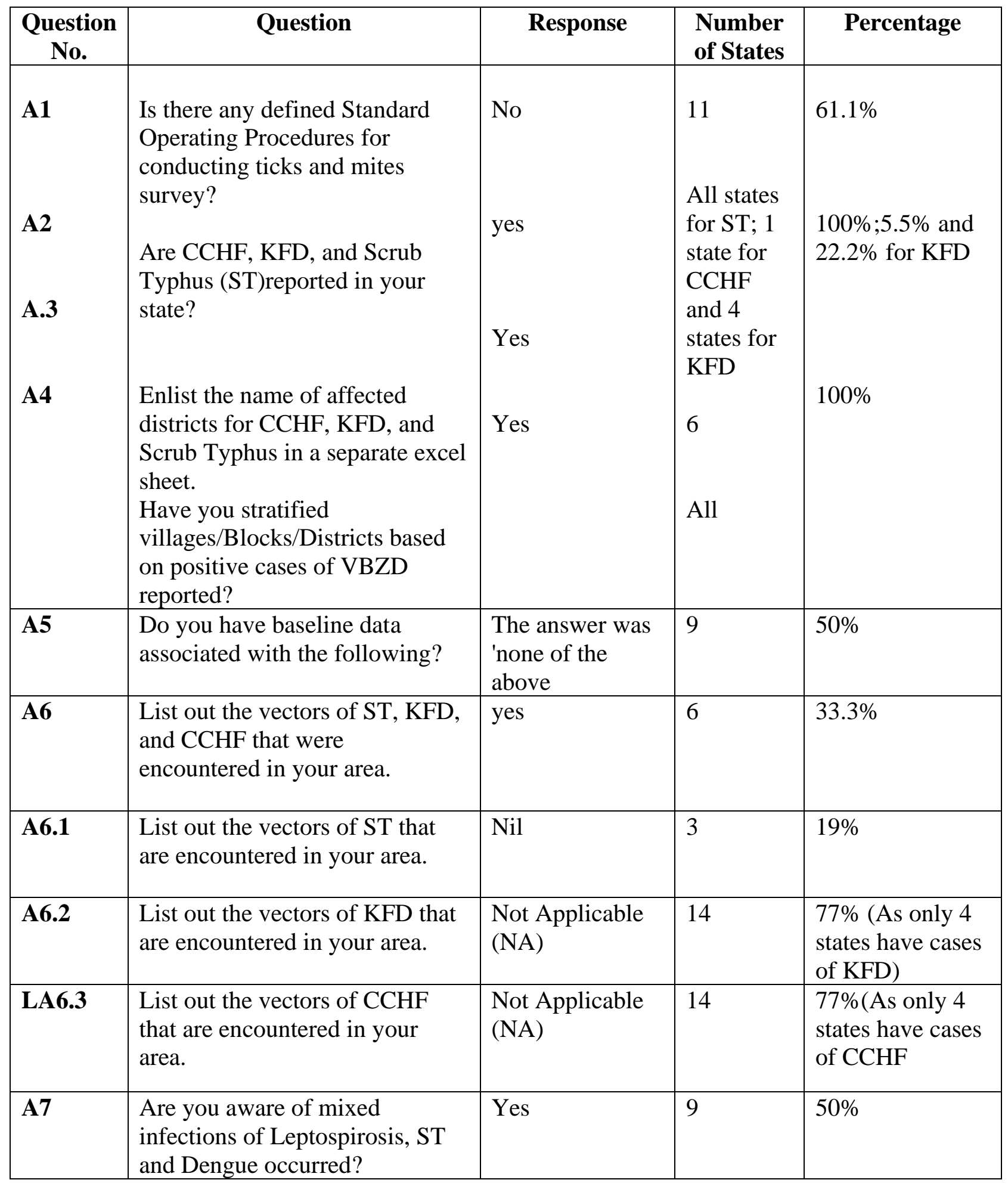




\begin{tabular}{|l|l|l|l|l|}
\hline A7.1 & $\begin{array}{l}\text { If yes do you have any lab } \\
\text { supported data on the mixed } \\
\text { infections }\end{array}$ & $\begin{array}{l}\text { None of the } \\
\text { states answered }\end{array}$ & 0 & 0 \\
\hline
\end{tabular}

Table-A2. Details of Questionnaire under Group-B framed for Entomological surveillance and their response

\begin{tabular}{|c|c|c|c|}
\hline Question & Frequent Answers & $\begin{array}{c}\text { Count of frequent } \\
\text { answers out of } 18 \\
\text { Respondents }\end{array}$ & Percentage \\
\hline $\begin{array}{l}\text { B.1 Did you frame any } \\
\text { Standard guidelines for } \\
\text { conducting Entomological } \\
\text { Surveillance? }\end{array}$ & None of the Above & 12 & $66.6 \%$ \\
\hline $\begin{array}{l}\text { B.2 Did you undertake any } \\
\text { faunistic survey for Mites in } \\
\text { your District } \\
\text { PHC/HSC/Village after } \\
\text { reporting a positive case of } \\
\text { Scrub Typhus (ST), } \\
\text { reported? }\end{array}$ & No & 11 & $61.1 \%$ \\
\hline $\begin{array}{l}\text { B.3 Did you undertake any } \\
\text { faunistic survey for Ticks in } \\
\text { your District } \\
\text { PHC/HSC/Village after } \\
\text { reporting a positive case of } \\
\text { CCHF and KFD reported? }\end{array}$ & No & 13 & $72.2 \%$ \\
\hline $\begin{array}{l}\text { B.4 How frequently do you } \\
\text { collect Ticks in vulnerable } \\
\text { places for VBZD? }\end{array}$ & Any Other & 11 & $61.1 \%$ \\
\hline $\begin{array}{l}\text { B.5 How frequently do you } \\
\text { collect Mites in places }\end{array}$ & Any Other & 12 & $66.6 \%$ \\
\hline
\end{tabular}




\begin{tabular}{|c|c|c|c|}
\hline vulnerable for VBZD? & & & \\
\hline B.5.1 Describe if any Other & Based on need & 1 & $5.5 \%$ \\
\hline $\begin{array}{l}\text { B.6 What frequency do you } \\
\text { collect Vectors in areas } \\
\text { where reporting positive } \\
\text { cases? }\end{array}$ & $\begin{array}{l}\text { Any Other (Whenever } \\
\text { cases reported) }\end{array}$ & 8 & $44.4 \%$ \\
\hline $\begin{array}{l}\text { B.7 Vector species for which } \\
\text { VBZD are encountered in } \\
\text { your state/District? }\end{array}$ & Scrub Typhus & 9 & $50 \%$ \\
\hline $\begin{array}{l}\text { B.7.2 If not, what is your } \\
\text { plan to survey Ticks and } \\
\text { Mites in positive cases } \\
\text { reported area? }\end{array}$ & $\begin{array}{l}\text { None of them } \\
\text { responded }\end{array}$ & 0 & 0 \\
\hline $\begin{array}{l}\text { B.8 Which methodology do } \\
\text { you for the collection of } \\
\text { Mites and Ticks from habitat } \\
\text { \& animals? }\end{array}$ & $\begin{array}{l}\text { None of them } \\
\text { responded }\end{array}$ & 0 & 0 \\
\hline $\begin{array}{l}\text { B.9 What are the challenges } \\
\text { for conducting } \\
\text { entomological surveillance } \\
\text { in your state in terms of } \\
\text { Infrastructure and logistics? }\end{array}$ & $\begin{array}{l}\text { Logistic supports } \\
\text { required }\end{array}$ & 18 & $100 \%$ \\
\hline $\begin{array}{l}\text { B.10 What technical and } \\
\text { logistics support do you } \\
\text { expect from State Govt and } \\
\text { NCDC to strengthen } \\
\text { entomological surveillance- } \\
\text { please provide details. }\end{array}$ & $\begin{array}{l}\text { Manpower and } \\
\text { Materials }\end{array}$ & 18 & $100 \%$ \\
\hline
\end{tabular}


Table-A3 Details of Questionnaire and they respond under Group-C (Vector Control Measures)

\begin{tabular}{|c|c|c|c|}
\hline Question & Frequent Answers & $\begin{array}{c}\text { Count of frequent } \\
\text { answers out of } 18 \\
\text { Respondents }\end{array}$ & Percentage \\
\hline $\begin{array}{l}\text { C.1 Whether there are } \\
\text { standard guidelines } \\
\text { available for Vector } \\
\text { Control measures? }\end{array}$ & None of the above & 11 & $61.1 \%$ \\
\hline $\begin{array}{c}\text { C.2 Which control } \\
\text { measure do you follow } \\
\text { to Control Mites and } \\
\text { Ticks? }\end{array}$ & None of the Above & 4 & $22.2 \%$ \\
\hline C.2.1 If Any Other & None of the Above & 0 & $0.0 \%$ \\
\hline $\begin{array}{l}\text { C.3 What other activities } \\
\text { do you undertake to free } \\
\text { of Ticks and Mites } \\
\text { infestation in affected } \\
\text { places? }\end{array}$ & NA & 3 & $16.6 \%$ \\
\hline $\begin{array}{l}\text { C. } 4 \text { Is there any system } \\
\text { in place to testing the } \\
\text { susceptibility of } \\
\text { insecticides? }\end{array}$ & No & 13 & $72.2 \%$ \\
\hline $\begin{array}{l}\text { C.6 Did you come across } \\
\text { resistance to insecticides } \\
\text { used for vector control } \\
\text { for any of the following } \\
\text { diseases? }\end{array}$ & Malaria & 10 & $55.5 \%$ \\
\hline $\begin{array}{l}\text { C.7 What are the } \\
\text { challenges observed } \\
\text { during vector control } \\
\text { activities in your state? }\end{array}$ & $\begin{array}{l}\text { Technical know-how; } \\
\text { Infrastructure Logistics; } \\
\text { Environmental Factors and } \\
\text { Growing Resistance }\end{array}$ & 3 & $16.6 \%$ \\
\hline
\end{tabular}


(Intersectoral Coordination)

Group-D

\begin{tabular}{|l|c|c|c|}
\hline \multicolumn{1}{|c|}{ Question } & $\begin{array}{c}\text { Frequent } \\
\text { Answers }\end{array}$ & $\begin{array}{c}\text { Count of frequent } \\
\text { answers out of 15 } \\
\text { Responses }\end{array}$ & Percentage \\
\hline $\begin{array}{l}\text { D.1 Do you have any regular communications } \\
\text { with State Veterinary/ Animal Husbandry } \\
\text { Department for undertaking ectoparasitic } \\
\text { surveillance predominant in the domestic } \\
\text { animal? }\end{array}$ & No & 9 & $50 \%$ \\
\hline D.1.1 If Yes, please provide details: & & 18 & $100 \%$ \\
\hline $\begin{array}{l}\text { D.2 What technical and logistics support do } \\
\text { you expect from State Government and NCDC } \\
\text { to strengthen Control/containment measures - } \\
\text { please provide details. }\end{array}$ & $\begin{array}{l}\text { Logistics } \\
\text { assistance } \\
\text { and } \\
\text { Manpower }\end{array}$ & & \\
\hline
\end{tabular}

Table-A4. Components arrived from resources available in the literature for developing strategies towards prevention and control of CCHF, KFD, and Scrub Typhus

\begin{tabular}{|c|c|c|}
\hline Surveillance and its outcomes & $\begin{array}{c}\text { Environmental } \\
\text { Health }\end{array}$ & $\begin{array}{l}\text { Entomological } \\
\text { Surveillance }\end{array}$ \\
\hline $\begin{array}{l}\text { General } \\
\text { 1. It is integrating the various } \\
\text { components that determine the } \\
\text { occurrence of disease. } \\
\text { 2. Ideally, the system will } \\
\text { compile data from human } \\
\text { surveillance (Human Cases). } \\
\text { 3. Veterinary surveillance } \\
\text { (Animal Hosts). } \\
\text { 4. Entomological surveillance } \\
\text { (Arthropod vectors). } \\
\text { 5. Environmental surveillance } \\
\text { (environmental risk factors). }\end{array}$ & $\begin{array}{l}\text { 1. In global travel } \\
\text { 2. Trade } \\
\text { 3. Urbanization and } \\
\text { tourism } \\
\text { 4. Climate change and } \\
\text { 5. Land use changes } \\
\text { and management } \\
\text { 6.. Temperature and } \\
\text { humidity } \\
\text { 7. Biodiversity } \\
\text { 8. Landscape } \\
\text { composition } \\
\text { 9. Frequent importation } \\
\text { of Hyalomin species } \\
\text { ticks into novel regions }\end{array}$ & $\begin{array}{l}\text { 1. Risk assessment } \\
\text { 2. Early warning } \\
\text { systems } \\
\text { 3. Identification of the } \\
\text { vector species } \\
\text { involved in } \\
\text { transmission events. } \\
\text { 4. Identification of } \\
\text { circulating pathogen } \\
\text { strain } \\
\text { 5. Optimizing vector } \\
\text { control in time and } \\
\text { space. } \\
\text { 6. Guidance for source } \\
\text { reduction campaign } \\
\text { 7. Insecticide resistance } \\
\text { Evaluating the efficacy }\end{array}$ \\
\hline
\end{tabular}




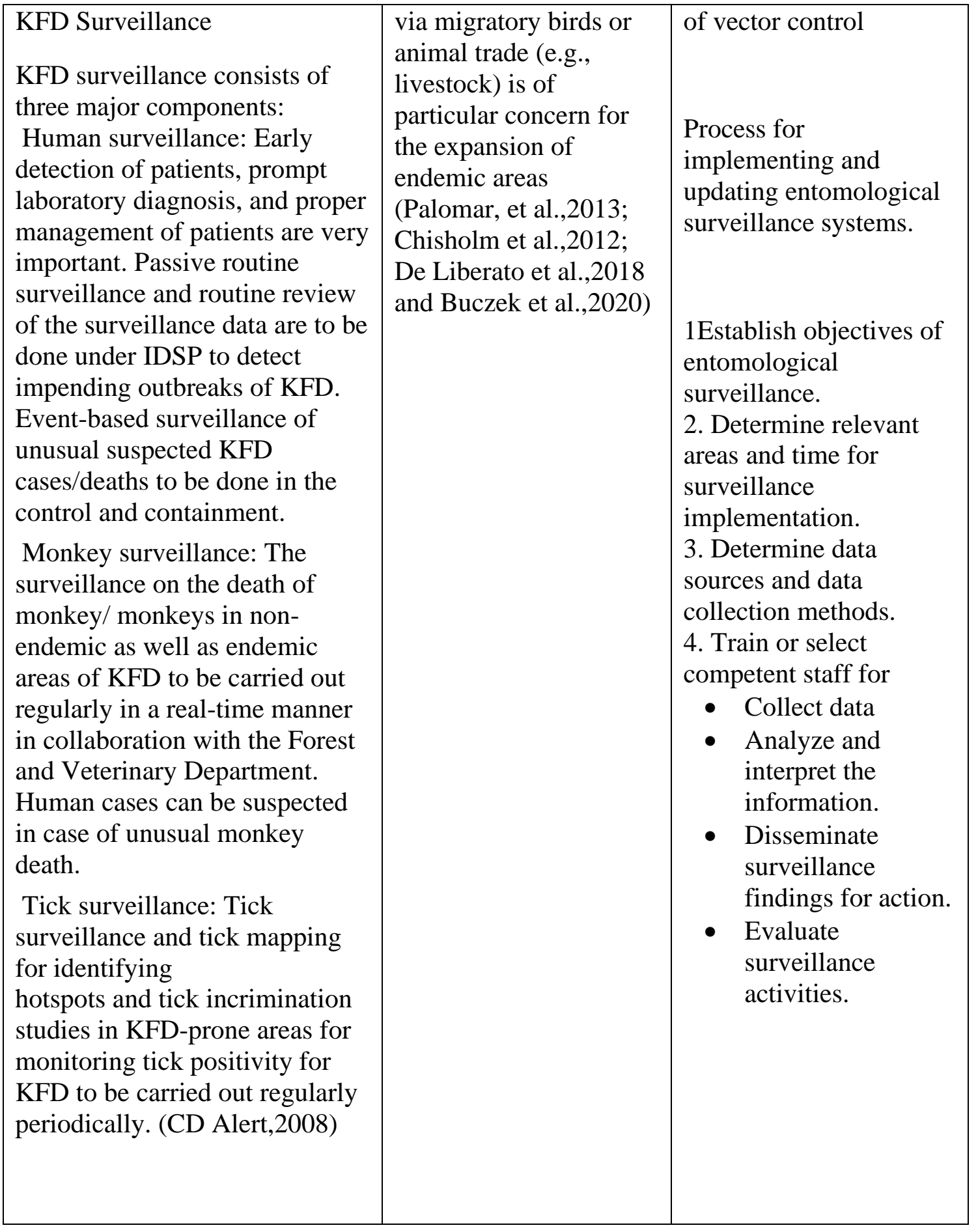


Table-A5. contd. Components arrived from resources available in the literature for developing strategies towards prevention and control of CCHF, KFD, and Scrub Typhus (ST)

\begin{tabular}{|c|c|c|}
\hline $\begin{array}{l}\text { Evaluation of the control and } \\
\text { prevention of CCHF concerning } \\
\text { Entomological surveillance }\end{array}$ & 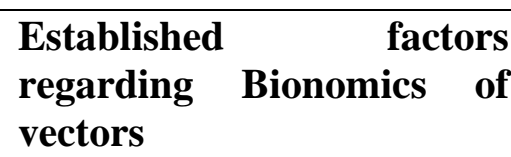 & $\begin{array}{l}\text { The behavior of } \\
\text { Ticks and mite } \\
\text { Vectors }\end{array}$ \\
\hline $\begin{array}{l}\text { 1. Density: There are two ways in it.1. } \\
\text { Man Hour Density. It is measured } \\
\text { through the total number of Ticks in an } \\
\text { hour by one manpower } \\
\text { 2. If ticks are collected from animals, } \\
\text { density is expressed as several } \\
\text { ticks/animal. } \\
\text { Mites } \\
\text { 3. Chigger Index: It is exclusively for } \\
\text { Mite Borne Disease. It is measured by } \\
\text { no. of chiggers infested by a single host. } \\
\text { 4. Prevalence Rate of mites: Number of } \\
\text { Hosts with ectoparasites/Total number of } \\
\text { hosts examined (Paul raj Philip Samuel et } \\
\text { al., 2021). } \\
\text { 5. Mean Intensity of ectoparasites from } \\
\text { host animals: Total number of } \\
\text { ectoparasites collected/Number of hosts } \\
\text { infected with ectoparasites (Paulraj Philip } \\
\text { Samuel et al., 2021). } \\
\text { 6. Tick Infection Rate: The detection of } \\
\text { viral antigen or genomic fragments in }\end{array}$ & $\begin{array}{l}\text { Transstadial Transmission: } \\
\text { In Ticks the infected blood } \\
\text { meal is taken by larval ticks, } \\
\text { the pathogens multiplied are } \\
\text { transmitted to nymphs and } \\
\text { adults and its significance, } \\
\text { ticks are acting as Reservoir. } \\
\text { Tran ovarian Transmission: } \\
\text { The pathogens taken in } \\
\text { blood meal are multiplied go } \\
\text { into eggs and it continues its } \\
\text { life cycle. It is commonly } \\
\text { found in mites, Ticks, and } \\
\text { Aedes spp mosquitoes. } \\
\text { Multiple Host life cycle: } \\
\text { some tick vectors exhibit } \\
\text { multiple host life cycles, in } \\
\text { which ticks in larval and } \\
\text { nymphal stages feed on } \\
\text { small mammalian hosts and } \\
\text { later switch to a different }\end{array}$ & $\begin{array}{l}\text { The behavior of the } \\
\text { chigger vectors } \\
\text { which are } \\
\text { remarkably hardy } \\
\text { and can survive } \\
\text { weeks of freezing or } \\
\text { immersion in water. } \\
\text { The established } \\
\text { vectors are all } \\
\text { species of the genus } \\
\text { Leptotrombidium } \\
\text { akamushi; } \\
\text { Leptotrombidium } \\
\text { deliense; L. pallidu } \\
\text { and L.scutellare } \\
\text { (Traub and } \\
\text { Wisseman,1968). } \\
\text { The infection rate of } \\
\text { Rickettsia in } \\
\text { tsutsugamushi in } \\
\text { vector species in } \\
\text { nature is believed to }\end{array}$ \\
\hline
\end{tabular}




\begin{tabular}{|c|c|c|}
\hline $\begin{array}{l}\text { tick vectors. It is calculated by the } \\
\text { number of Ticks vectors positive with } \\
\text { CCHFV/Number of Ticks tested*100. Its } \\
\text { critical Rate is found } 2.78 \% \text { (Spengler et } \\
\text { al., 2017; Leggiadro, } 2017 \text { and Estrada- } \\
\text { Peña et al., 2012). } \\
\text { Olson et al,2019 estimated a minimum } \\
\text { requirement of } 0.69 \text { chiggers per shrew } \\
\text { as the critical abundance needed to result } \\
\text { in } 1 \text { human case per month } \\
\text { Host vector infestation rate Proportion of } \\
\text { hosts infected by the vector. Divide by } \\
\text { host species and location, if possible, } \\
\text { provide vector species composition. } \\
\text { NDVI: } \\
\text { Vegetation Index (NDVI): This Index is } \\
\text { due to the latest development in ecology } \\
\text { to predict herbivore and non-herbivore } \\
\text { animals in a place (Nathellie Pettorelli et }\end{array}$ & $\begin{array}{l}\text { larger mammalian host as } \\
\text { adults to complete their life } \\
\text { cycle. The vector of CCHF } \\
\text { Hyalomma species has a } \\
\text { two-host life cycle. (Bente et } \\
\text { al.,2013. This phenomenon } \\
\text { increases the reservoir of } \\
\text { CCHFV. } \\
\text { Co-feeding: During feeding, } \\
\text { ticks produce pheromones } \\
\text { that attract other ticks to the } \\
\text { same feeding pool, } \\
\text { facilitating tick-to-tick } \\
\text { transmission, a process } \\
\text { accelerated by the presence } \\
\text { of tick saliva (Jones et al., } \\
\text { 1987). }\end{array}$ & $\begin{array}{l}\text { be low, and chiggers } \\
\text { may be serving as } \\
\text { reservoirs of } \\
\text { infection and not just } \\
\text { as vectors. } \\
\text { Vector infestation } \\
\text { rate and index, } \\
\text { vector collection } \\
\text { method, habitat } \\
\text { description, rainfall } \\
\text { during the study, } \\
\text { minimum, maximum } \\
\text { and mean } \\
\text { temperature during } \\
\text { the study, and } \\
\text { laboratory test used } \\
\text { (Ivo Elliott, et al ). } \\
\text { Tsutsugamushi- } \\
\text { infected free-living } \\
\text { larvae should be } \\
\text { considered potential } \\
\text { vectors, although not } \\
\text { necessarily } \\
\text { humans. }\end{array}$ \\
\hline
\end{tabular}


Figure-A1. The scenario of Scrub typhus, KFD, and CCHF cases in India concerning reports sent by states for the National Review Meeting.

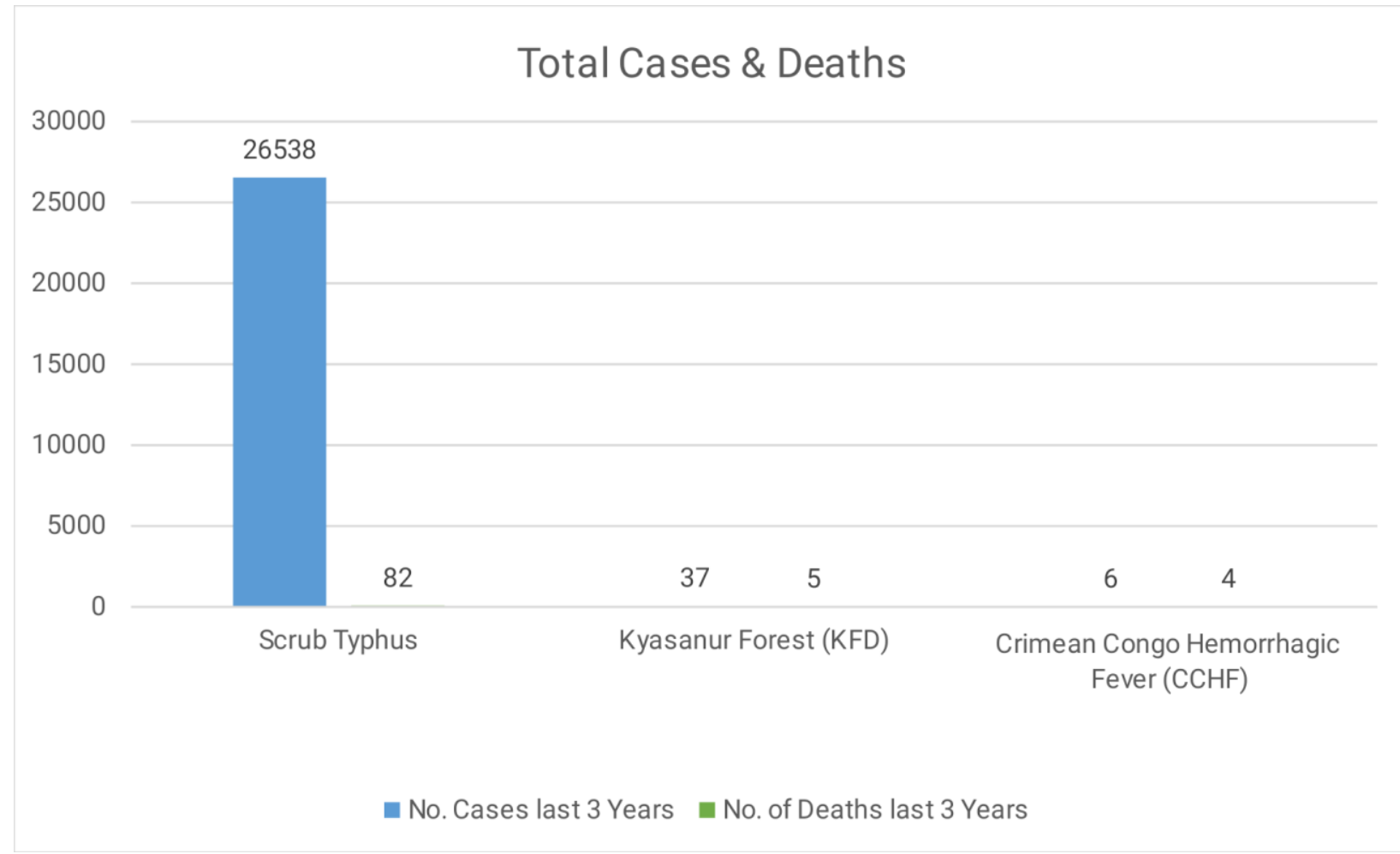




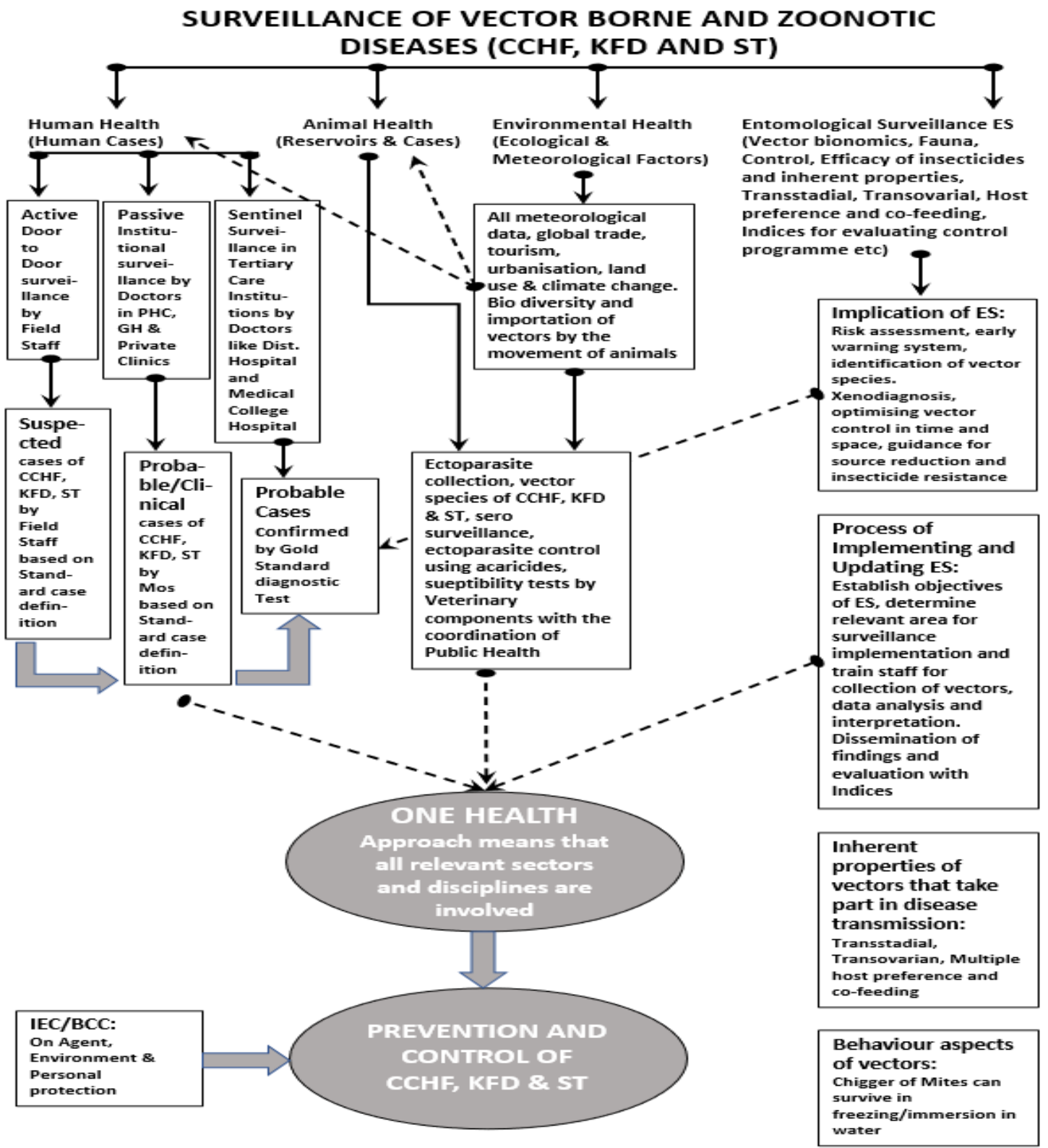

Figure 2: Flow Chart for the implementation of probable strategies by Integrating components of Human-Animal-Environmental Health under the concept of 'ONE HEALTH' for the control \& Prevention of CCHF, KFD \& ST 